Relato de Caso

CASE REPORT

\title{
Uso do Pamidronato na Síndrome SAPHO
}

\section{Pamidronate Treatment in SAPHO Syndrome}

\author{
Luana Gerheim Machado ${ }^{(1)}$, Ana Andrade Capp ${ }^{(1)}$, Maria Alice da Silva Paes ${ }^{(1)}$, \\ Ricardo Baesso de Oliveira ${ }^{(2)}$, Herval de Lacerda Bonfante ${ }^{(3)}$
}

\section{RESUMO}

A síndrome SAPHO é uma condição relativamente rara e ainda pouco diagnosticada, porém com características bem definidas que deram origem ao seu epônimo: Sinovite, Acne, Pustulose, Hiperostose e Osteíte. O diagnóstico é realizado pela análise dos dados clínicos, laboratoriais e exames de imagem, com destaque importante para a cintilografia óssea. O pamidronato é um bisfosfonato de segunda geração que afeta a remodelação óssea e demonstra propriedades antiinflamatórias, sendo uma opção para o tratamento desta entidade. Com este relato de caso, objetivamos lembrar da existência da síndrome SAPHO e do uso do pamidronato em seu tratamento.

Palavras-chave: SAPHO, cintilografia óssea, pamidronato.

\section{INTRODUÇÃO}

A síndrome SAPHO foi descrita pela primeira vez em 1987 por Chamot et a ${ }^{(1)}$ para designar um grupo de desordens com manifestações osteoarticulares e dermatológicas associadas. A sigla SAPHO representa os maiores achados: Sinovite, Acne, Pustulose, Hiperostose e Osteíte. Pode ocorrer em qualquer idade, com início principalmente em crianças e adultos jovens.

O envolvimento cutâneo é caracterizado tipicamente por pustulose palmoplantar e acne severa ou conglobata, mais comumente em face e dorso, podendo ou não estar presentes no momento da descoberta das lesões esqueléticas ${ }^{(1)}$.

O envolvimento osteoarticular na síndrome SAPHO é caracterizado por hiperostose, osteíte e sinovite ${ }^{(2,3)}$. A hipe-

\begin{abstract}
Although relatively rare and still not frequently diagnosed, SAPHO syndrome has specific features that originated the acronym: Synovitis, $\boldsymbol{A}$ cne, $\boldsymbol{P}$ ustulosis, $\boldsymbol{H}$ yperostosis and $\boldsymbol{O}$ steitis. Diagnosis is made possible through a combination of clinical manifestations, laboratory findings, and radiological exams, with bone scintigraphy playing a prominent role. Pamidronate is a second-generation bisphosphonate that affects bone turnover and exhibits anti-inflammatory properties, being a treatment option for this entity. With this case report, we aim to draw attention to SAPHO syndrome and the use of Pamidronate for its treatment.
\end{abstract}

Keywords: SAPHO; scintigraphy; pamidronate.

rostose é evidenciada por um osso trabecular e esponjoso espesso. A cavidade medular se torna estreita e a superfície externa do osso pode ser irregular. Aparece radiologicamente como esclerose óssea. Osteíte refere-se à inflamação óssea, sendo demonstrada pelo exame histopatológico como infiltrado inflamatório estéril. Essas lesões afetam usualmente a parede torácica ântero-superior, vértebras e pelve, porém podem ainda envolver mandíbula e ossos longos ${ }^{(4,5,6)}$.

A maioria dos pacientes tem sinovite axial ou periférica intermitentes. Encontra-se uma alta prevalência (acima de 90\%) de envolvimento axial e $40 \%$ dos pacientes afetados têm uma evidência clara de sacroileíte. Por estes motivos, muitos autores classificam a síndrome SAPHO como uma espondiloartropatia ${ }^{(4)}$.

Trabalho realizado no Serviço de Reumatologia da Santa Casa de Misericórdia de Juiz de Fora (SCMJF). Recebido em 24/02/2005. Aprovado, após revisão, em 03/10/2005

1. Acadêmica de Medicina da Universidade Federal de Juiz de Fora (UFJF), Estagiária do Serviço de Reumatologia da SCMJF.

2. Professor Colaborador do Departamento de Farmacologia da UFJF, Reumatologista, Coordenador do Internato em Medicina da SCMJF.

3. Professor Assistente do Departamento de Farmacologia da UFJF, Reumatologista, Chefe do Serviço de Reumatologia da SCMJF.

Endereço para correspondência: Herval de Lacerda Bonfante, Rua Capitão Arnaldo de Carvalho, 693/301, Jardim Glória, Juiz de Fora, CEP 36036-180, MG, Brasil, e-mail: hervalbonfante@terra.com.br 
Não existem exames específicos para o diagnóstico da síndrome SAPHO, entretanto, o acometimento de articulações esternoclaviculares ou de parede torácica anterior, associado à presença de acne severa em paciente jovem devem levantar suspeita deste diagnóstico. Quanto aos exames complementares, que são inespecíficos, podemos encontrar alterações nas provas inflamatórias. A cintilografia é importante para a detecção dos locais acometidos, evidenciando hipercaptação nestas áreas.

Não há tratamento específico para a síndrome SAPHO. A terapêutica utilizada envolve principalmente analgésicos e antiinflamatórios não-esteroidais. Outros agentes podem ser usados, incluindo metotrexato, corticosteróides orais, colchicina, sulfassalazina, ciclosporina e anti TNF- $\boldsymbol{\alpha}^{(4,7)}$.

Outra opção que vem sendo relatada é o pamidronato, um bisfosfonato de segunda geração que inibe a reabsorção e o remodelamento ósseos com significativas propriedades antiinflamatórias $^{(4,8)}$.

Desta forma, discutimos a partir deste relato de caso as características da síndrome SAPHO e o uso do pamidronato como opção terapêutica nos casos refratários.

\section{RELATO DE CASO}

Paciente RCR, 16 anos, masculino, branco, estudante, natural e residente em Juiz de Fora (Minas Gerais), foi atendido em fevereiro de 2003 com relato de dor difusa pelo corpo, há aproximadamente dois meses, iniciada após exercício físico intenso. Referia ser mais intensa em região torácica anterior, principalmente esternal, irradiada para o dorso. Negava dor em articulações periféricas. Relatava episódios de febre nos últimos dias.

Ao exame físico apresentava bom estado geral. Temperatura axilar: $38^{\circ} \mathrm{C}$, acne severa em face, dorso (Figura 1) e região torácica anterior, com pústulas e sangramento em algumas lesões. Dor intensa à digitopressão de 1/3 médio e superior do esterno e articulação esternoclavicular esquerda. Não apresentava artrite periférica.

Quanto aos exames complementares, o hemograma evidenciava uma leucocitose, com leucometria total de $12.200 / \mathrm{mm}^{3}$, série vermelha normal, velocidade de hemossedimentação (VHS) $1^{a}$ hora $=40 \mathrm{~mm}$, proteína $\mathrm{C}$ reativa $(\mathrm{PCR})=50 \mathrm{mg} / \mathrm{dl}($ Normal até $6 \mathrm{mg} / \mathrm{dl})$. A radiografia de tórax era normal e foi então solicitada cintilografia óssea para melhor avaliação do quadro álgico. Esta última mostrou hipercaptação em articulações esternoclaviculares mais intensa à esquerda e 1/3 médio da região esternal (Figura 2). A Ressonância Nuclear Magnética de articulação esternoclavicular esquerda confirmou as lesões com aspecto inflamatório e o ecocardiograma estava normal.

Inicialmente, a hipótese foi de a origem ser infecciosa. O paciente foi internado e iniciada terapêutica intravenosa com oxacilina e ciprofloxacino associados a paracetamol e codeína via oral para o quadro álgico. Após 14 dias, houve melhora parcial da dor. Teve alta hospitalar com ciprofloxacino oral e indometacina $25 \mathrm{mg}$ de $8 / 8 \mathrm{~h}$, sendo que após seis semanas apresentava normalização da leucocitose e redução da VHS $(22 \mathrm{~mm})$ e PCR (32 mg/dl), quando foi suspensa a antibioticoterapia.

Após alguns dias, evoluiu com dor intensa em membro inferior direito, sendo submetido à nova cintilografia óssea em março de 2003 que mostrou captação menos intensa nas áreas anteriormente visualizadas, porém com captação em sacroilíacas, principalmente à direita.

Diante do afastamento de etiologia infecciosa foi feito o diagnóstico de síndrome SAPHO. A dose de indometacina foi aumentada para $150 \mathrm{mg} / \mathrm{dia}$. Não havendo melhora, foi associada sulfassalazina $1 \mathrm{~g}$ /dia com elevação da dose para $2 \mathrm{~g} /$ dia, seguida de estabilização do quadro. Após seis meses (setembro de 2003), foi realizada cintilografia óssea de controle que não mostrou alterações evolutivas. Hemograma e VHS estavam normais.

Em outubro de 2003, persistia queixa de muita dor em região esternal e esternoclavicular esquerda. Decidimos iniciar pamidronato $60 \mathrm{mg}$ intravenoso em infusão de 4 horas de duração. Houve melhora acentuada do quadro álgico. Em janeiro de 2004 voltou a ficar sintomático, sendo repetida a dose de pamidronato com significativa melhora. Nova cintilografia óssea realizada em abril de 2004 evidenciou melhora em relação aos estudos prévios, com ausência de captação em articulações sacroilíacas. Atualmente, o paciente utiliza indometacina $50 \mathrm{mg} /$ dia e mantém-se assintomático, com provas inflamatórias dentro dos parâmetros de normalidade.

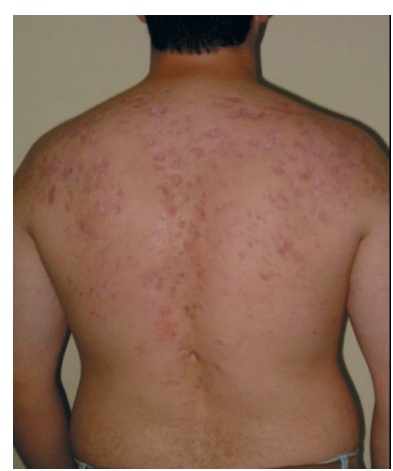

Figura 1 - Acne severa em região dorsal 


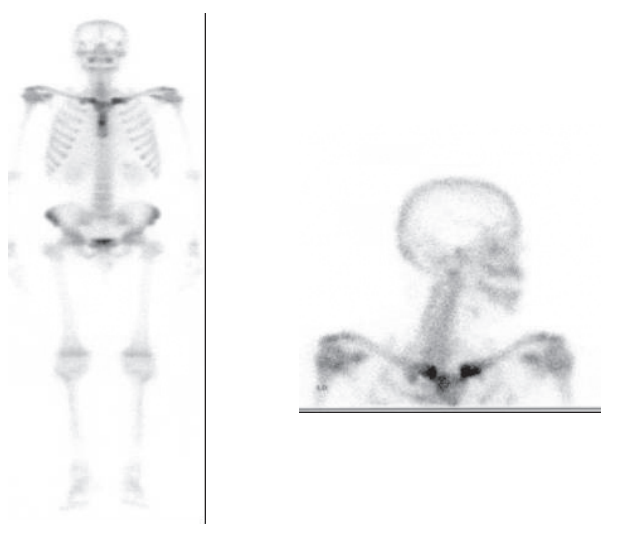

Figura 2 - Hipercaptação em região esternal e nas articulações esternoclaviculares

\section{DISCUSSÃO}

Em 1987, Chamot et al(1) utilizaram o nome de síndrome SAPHO para agrupar uma série de doenças que teriam como achados comuns o comprometimento ósseo, caracterizado por osteíte asséptica, afetando principalmente articulações da parede torácica anterior, acometimento cutâneo dado por pustulose palmoplantar e acne severa e, em muitos dos casos, associada à sacroileíte. A etiologia e patogênese da síndrome SAPHO permanecem controversas ${ }^{(1,9)}$.

Uma das evidências que suportam um mecanismo fisiopatológico comum das síndromes ósseas e cutâneas tem sido um crescimento lento de microorganismos da espécie Propionibacterium acnes nas áreas afetadas. Porém, biópsias ósseas e articulares são geralmente negativas para sua presença e a terapia antimicrobiana é usualmente ineficaz ${ }^{(1,2,9)}$.

A síndrome SAPHO tem sido relatada dentro do grupo das espondiloartropatias soronegativas devido a algumas similaridades tais como: sacroileíte e entesopatias, associações com lesões psoriásicas e artropatias enteropáticas, prevalência de antígeno HLA-B27, mais alta que na população geral, e terapêutica antiinflamatória usualmente efetiva ${ }^{(1,9)}$.

Achados laboratoriais sugestivos de doença inflamatória são freqüentemente encontrados como elevação das proteínas de fase aguda. O fator reumatóide é usualmente negativo. O HLA-B27 é positivo em menos de 30\% dos casos. A cintilografia óssea revela hipercaptação nas áreas afetadas. No paciente relatado, havia alteração das provas inflamatórias, leucocitose que fazia pensar em quadro infeccioso e a presença de acne severa, inclusive com lesões abertas e apresentando sangramento constituindo mais uma possibilidade de a sua origem ser infecciosa, que foi descartada após insucesso com a terapêutica antimicrobiana. O HLA-B27 foi negativo, e a cintilografia óssea foi indicada pelo relato difuso de dor e rastreamento de outras articulações.

Os bisfosfonatos, como o pamidronato, são análogos sintéticos dos pirofosfatos e potentes inibidores de reabsorção óssea, constituem-se em agentes terapêuticos importantes na doença de Paget, mieloma múltiplo, hipercalcemia associada a doenças malignas, metástases ósseas e osteoporose ${ }^{(1)}$. Apresentam, assim, importante papel nas condições que cursam com osteogênese excessiva. Em relação ao mecanismo de ação, promovem efeitos supressores da reabsorção óssea por inibirem a formação e recrutamento de osteoclastos jovens e promovem apoptose dos maduros ${ }^{(10,11)}$. Existem evidências de que os bisfosfonatos atuem no processo inflamatório crônico ao suprimir as citocinas IL-1, Il-6 e TNF- $\alpha$, embora este mecanismo esteja apenas parcialmente elucidado ${ }^{(12,13)}$.

Os bisfosfonatos têm sido bem tolerados e parecem promover remissão em todos os componentes dessa desordem: ossos, articulações e envolvimento cutâneo, levando à melhora na função, bem-estar e alívio da dor $^{(4)}$.

$\mathrm{O}$ uso do pamidronato intravenoso tem se mostrado promissor para o tratamento das exacerbações da síndrome SAPHO refratárias ao tratamento convencional ${ }^{(1,4,7,8)}$

Quanto a doses e intervalos de uso, não existe um consenso. No caso relatado, utilizamos duas doses de $60 \mathrm{mg}$ em cada infusão com intervalo de três meses, de acordo com reaparecimento do sintoma dor. Sayag-Boukris et a ${ }^{(14)}$ trataram seis pacientes com $60 \mathrm{mg}$ de pamidronato intravenoso por três dias consecutivos. Todos seis tiveram uma melhora da dor de no mínimo 50\% dentro de duas semanas da infusão. Amital et a ${ }^{\left({ }^{(4)}\right.}$ relataram dez casos com a utilização de um a quatro ciclos em intervalos de quatro meses.

Não tivemos nas duas infusões nenhum efeito adverso relatado pelo paciente, entretanto, podem ocorrer febre, sintomas gripais, leucopenia transitória e hipocalcemia como efeitos adversos ${ }^{(7)}$.

Kopterides et al ${ }^{(15)}$ relataram sucesso no tratamento utilizando um outro bisfosfonato - o ácido zoledrônico - em um caso refratário.

No caso apresentado, houve uma confirmação dos resultados positivos obtidos com o uso do pamidronato no tratamento da síndrome SAPHO, possibilitando controle da dor e menor utilização de antiinflamatórios. No entanto, em relação ao acometimento cutâneo, o paciente utilizou isotretinoína, havendo melhora acentuada do quadro de acne, o que prejudicou a avaliação do pamidronato nesta manifestação.

Existem relatos de uso do pamidronato em crianças e adolescentes, com segurança tanto na síndrome $\mathrm{SAPHO}^{(7)}$ 
como na osteogênese imperfeita ${ }^{(16)}$, nesta última, em crianças abaixo de 36 meses de idade.

Neste caso, o quadro álgico, principalmente em articulação esternoclavicular esquerda e região esternal, refratária ao uso de antiinflamatórios e sulfassalazina, nos fez pensar em outra abordagem. Alguns autores preconizam o uso de glicocorticóides, metotrexato, ciclosporina e anti-TNF- $\mathbf{\alpha}^{(4,7)}$ Optamos pela utilização do pamidronato por acreditarmos em menor toxicidade e esquema de mais fácil adesão. No entanto, outros estudos controlados, envolvendo tratamento a longo prazo e em um grande número de pacientes, se mostram necessários para confirmar a eficácia e doses ideais.

\section{REFERÊNCIAS}

1. Chamot AM, Benhamou CL, Kahn MF, Beraneck L, Kaplan G, Prost A: Le Syndrome Acné pustulose Hyperostose Ostéite (SAPHO). Rev. Rhum 54:187-196, 1987.

2. Boutin RD, Resnick D: The SAPHO Syndrome: an evolving concept for unifying several idiopathic disorders of bone and skin. Am J Roentgenol 170: 585-591, 1998.

3. Earwaker JWS, Cotten A: SAPHO: syndrome or concept? Imaging findings. Skeletal Radiol 32:311-327, 2003.

4. Amital H, Applbaum YH, Aamar S, Daniel N, Rubinow A: SAPHO syndrome treated with pamidronate: an open-label study of 10 patients. Rheumatol: 658-661,2004.

5. Sugimoto H, Tamura K, Fugii T: The SAPHO syndrome: defining the radiological spectrum of diseases comprising the syndrome. Eur Radiol 8:800-806, 1998.

6. Cotten A, Flipo RM, Mentre A, Delaporte E, Duquesnoy B, Chastanet P: SAPHO syndrome. Radiographics: 1147-1154, 1995.

7. Kerrison C, Davidson JE, Cleary AG, Beresford MW: Pamidronate in the treatment of childhood SAPHO syndrome. Rheumatology 43: 1246-1251, 2004.

8. Courtney PA, Hosking DJ, Fairbairn, KJ, Deighton CM: Treatment

of SAPHO with pamidronate. Rheumatol 41:1196-1198, 2002.

9. Jahangier ZN, Jacobs JW, Bijlsma JW: SAPHO syndrome: common denominator for various bone and skin diseases. Ned Tijdschr Geneeskd.141: 764-769, 1997.

10. Allgrove J: Biphosphonates. Arch Dis Child 76:73-75,1997.

11. Plotkin LI, Weinstein RS, Parfitt AM, Roberson PK, Manolagas SC, Bellido T: Prevention of osteocyte and osteoblast apoptosis by bisphosphonates and calcitonin. J Clin Invest 104: 1366-1374, 1999.

12. Pennanen N, Lapinjoki S, Urtti A. Monkkonen J: Effect of liposomal and free bisphosphonates on the IL-1, IL-6 and TNF-alpha secretion from RAW 264 cells in vitro. Pharm Res 12: 916-922, 1995.

13. Hayem G. Bouchard-Chabot A. Benali K et al: SAPHO syndrome: a long-term follow-up studt of 120 cases. Semin Arthritis Rheum 29:332-334, 1999

14. Sayag-Boukris V, Laoussadi S, Perrot S. Laroche F, Menkes CJ, Kahan A. Efficacy of pamidronate in the treatment of sapho syndrome. Arthritis Rheum.41(Suppl. 9): S 114, 1998.

15. Kopterides P, Pikazis D, Koufos C: Successful treatment of SAPHO syndrome with zoledronic acid. Arthritis Rheum 50: 2970-3, 2004.

16. Dimeglio LA, Ford L, McClintock C, Peacock M. Intravenous pamidronate treatment of children under 36 months of age with osteogenesis imperfecta Bone 35: 1038-45, 2004. 